Population Study

Poster

Abstract ID: 81

\title{
Misconceptions about disease among parents of thalassaemic patients: A qualitative study
}

\author{
Nora Mat Zin ${ }^{\mathrm{a}}$ | Naznin Muhammad ${ }^{\mathrm{a}}$ | Kamaruzaman Wan Su ${ }^{\mathrm{b}}$ | Suzanah Abdul Rahman ${ }^{\mathrm{c}}$ \\ ${ }^{a}$ Kulliyyah of Medicine, International Islamic University Malaysia \\ ${ }^{b}$ Kulliyyah of Nursing, International Islamic University Malaysia \\ 'Kulliyyah of Allied Health Science, International Islamic University Malaysia
}

Introduction: Poor understanding and knowledge about thalassaemia has been associated with a poor attitude towards the disease as a whole. Thus, it is the aim of this study to explore the poor attitude and misconceptions about thalassaemia among the parents of thalassaemic patients. Methods: This study was conducted over a six-month period. Five focus group sessions (5-6 per group) involving different sets of parents of thalassaemia patients attending the Paediatric Clinic of Tengku Ampuan Afzan Hospital, Kuantan, Pahang, Malaysia was carried out. Results: The study reveals that misconceptions associated with thalassaemia are still prevalent as shown in our study. Misconceptions that we encountered were related to the underlying cause, sign and symptoms, blood transfusion therapy and iron chelation therapy. Such incorrect knowledge was observed among parents coming from different educational backgrounds and socioeconomic status. As a result of misconceptions parents opt for alternative medicine or to seek treatment from traditional healers for thalassaemia. Conclusions: Several misconceptions still continue despite the nationwide campaign on screening programme to increase awareness about the disease. More effort is needed to improve the knowledge of the parents of thalassaemic patients as they have direct influence on the supervision of the management of thalassaemia patients.

KEYWORDS: Misconception, Thalassaemia 